This item was submitted to Loughborough's Research Repository by the author.

Items in Figshare are protected by copyright, with all rights reserved, unless otherwise indicated.

\title{
Investigation on grid-scale BESS providing inertial response support
}

PLEASE CITE THE PUBLISHED VERSION

http://dx.doi.org/10.1109/POWERCON.2016.7754049

PUBLISHER

(c) IEEE

VERSION

AM (Accepted Manuscript)

LICENCE

CC BY-NC-ND 4.0

REPOSITORY RECORD

Alhejaj, Samir M., and Francisco M. Gonzalez-Longatt. 2019. "Investigation on Grid-scale BESS Providing Inertial Response Support”. figshare. https://hdl.handle.net/2134/23096. 


\title{
Investigation on Grid-Scale BESS Providing Inertial Response Support
}

\author{
S. M. Alhejaj, Member, IEEE, and F. M. Gonzalez-Longatt, Senior Member, IEEE
}

\begin{abstract}
The importance of Energy Storages System (ESS) without a doubt is started to compete for the importance of Renewable Energy System (RES) nowadays and in the near future. ESS such as grid-scale batteries has the advantage of storing energy and provides many other services and functionalities to the power system. This paper investigates the effect of installing Battery Energy Storage System (BESS) on grid level transmission system to support fast Inertial Frequency Response (IR). Details of the BESS modeling are presented in this paper. The main contribution is to demonstrate that inertial response provided by BESS can create change to the Rate of Change of Frequency (ROCOF), providing frequency support and improving the system frequency response. A simple test system is used to investigate the effect of the inertial controller in BESS to support the system frequency response. Many time domain simulation tests using DIgSILENT PowerFactory are carried out to evaluate the effect of installing BESS with inertial response enabled. The time-domain simulations are conducted to demonstrate the system frequency responses considering: (i) gain of the inertial controller (ii) different sizes of disturbances, (iii) system robustness.
\end{abstract}

Index Terms-- Frequency, Inertial Response, Grid-Scale Energy Storage, Transmission system.

\section{INTRODUCTION}

$\mathrm{T}$ HE structure of the power system is changing shape toward new transformation era of electricity production with the encouragement of all current advances in technologies such as communication, monitoring, power electronics, control systems and phasor measurement units. As a result, the conventional power system transformation for different shape becomes applicable to integrate more continuously added sustainable generation resources. However, some of the electrical systems critical issues like system stability and power quality are regularly affected by this transformed infrastructure since most related control strategies are configured to work with conventional electricity generation. Furthermore, frequency stability is the most venerable and affected facet among other power system stability matters within this essential change [1]. Most existing frequency stability control methodologies such as secondary

S. M. Alhejaj is with the Department of Wolfson School of Mechanical, Electrical \& Manufacturing Engineering, Loughborough University, Leicestershire, LE113TU, UK (s.m.alhejaj@lboro.ac.uk)

Francisco M. Gonzalez-Longatt is with the Department of Wolfson School of Mechanical, Electrical \& Manufacturing Engineering, Loughborough University Leicestershire, LE11 3TU, UK (fglongatt@fglongatt.org) and tertiary are still effective to work in the present state of the system. However, Primary Frequency Control (PFC) is facing the greatest challenge to cope with this change [2]. Principally, PFC consists of two relatively fast responses: inertial response and governor control. The latter is a response that can be provided by increasing the active power that is supplied by dispatched online generators. The former is continuously declining due to the reduction in the number of the conventional power generating units due to the continuously added RES units. IR is an inherited system property that mainly relies on the kinetic energy which stored in the total of all rotating mass of the generation and load machines [3].

Energy storage could provide a surplus for the declined inertia due to their fast response [4]. The new advanced generation of BESS and their falling prices could be a large step toward replacing the fast-fired gas turbine that is used as a reserve whenever it is needed to provide the necessary active power for frequency stability. Air-metal batteries such as AirAluminum and Air-Zinc [1] with high energy density are already used for military and industrial applications [5].

This paper considers the effect of installing BESS on grid level transmission system to support fast inertial frequency response. The paper is structured in four sections: Section II presents literature review about some of the methods that are used to emulate the inertial response. Section III provides details of the grid model and BESS that are used in simulation tests to prepare this paper, including particulars of the inertial controller. In the following section IV, time domain simulation and results are presented, and the main issues that are related to IR control are discussed. Finally, the last section includes conclusions remarks and references.

\section{EMULATED INERTIAL FREQUENCY RESPONSE CONTROL METHODOLOGY}

After a disturbance due to generation-demand unbalances, the system frequency may deviate above or below its scheduled value [6]. As a result, the system frequency drops based on the amount of active power loss due the trip of generation unit or rises due to a sudden loss of load. Control strategies for frequency regulation are necessary to bring the frequency to its scheduled value. Current frequency strategies are discussed in several research papers [3]-[5]. Due to the decoupling of the new RES such as the wind and solar through converters, there is no inertia supplied by most RES 
to the grid. The declined inertia should be substituted, and alternative method should be implemented to manage the frequency stability. The declined inertia can be compensated by emulated inertia by integrating BESS and using an appropriate control methodology. Inertia emulation technique is typically based on the swing equation (3) which represents the relationship between the rate of change between the mechanical and electrical powers.

\section{A. Inertia Emulating Techniques in Wind and Solar Power}

The two main disputes with integrating RES into power grid are the quality of output power due to the fluctuating and declining inertia both of which affect the frequency operation and control of power system [7]. The first problem is caused by the fluctuating power which should be dealt with and retained at a certain level. However, this issue is outside the scope of this paper. The second issue is related to the declined inertia, and it will be the main theme of this paper.

Several control techniques proposed by many researchers and used commercially in wind turbines and solar energy to emulate inertia response and to support grid frequency without using BESS. One of these methods is by using Maximum Power Point Tracking (MPPT) control technique [8]. The most used type of wind turbines currently is Variable-Speed Wind Turbine (VSWT) which is coming in two categories [9]:

(i) Doubly Fed Induction Generators (DFIGs) and (ii) Permanent Magnet Synchronous Generators (PMSGs). Most newly installed wind turbines such as DFIG and PMSG entirely lack inertia because the electronic decoupling with the power grid. An alternative approach to gain a short-term frequency control is to add a supplementary loop to the VSWT control system [10]. This control technique is relying solely on the rotor speed variation. Therefore, the inertia constant is a function of that change in speed [11].

\section{B. Inertia Emulating Techniques Using BESS}

BESS serves many purposes and suits many applications. It replaces several existing technologies which are used currently to control the power flow or those used for the purpose of correcting some of the power system parameters. For example, it could be used to replace currently in use ancillary services such as Load-Frequency Control (LFC) [12] or Static Voltage Comparator (STATCOM) [13]-[14]. Based on the required application, batteries require a control technique and therefore a controller that can provide the necessary function. Regardless of the purpose and the application that BESS is used for only its components rating and controller design are varying to suit the application that is needed for that particular purpose. Many researchers have promoted many control strategies.

Some of these strategies are more appropriate for a particular application while other is generic. Reference [14] discuses BESS as a replacement for FACT system with a controller that reacts to the change in power flow through transmission lines. Whereas [12] suggests a Proportionalintegral (PI) controller for active power compensation in a microgrid with installed Photovoltaic (PV) generation.
Specific controller design, mainly for the inertial response, is discussed by [15] who follow an approach that been discussed widely in the research papers and what so called a virtual synchronous generator (VSG) to emulate the power exchange between the inertia of this fictitious synchronous generator and a grid. Similarly, based on the same idea, two stages BESS technique is proposed by [16] to mimic the operation of the conventional synchronous generator plant to provide the necessary fast inertial response. However, [17] took a different approach to providing a control strategy likely to be more generic for BESS to provide active and reactive power so that BESS acts like a synchronous generator. Frequency Regulation control could also be implemented through the concept of Virtual Power Plant (VPP). Bigger projects that used to provide frequency regulation solutions using aggregated BESS discussed in [18].

Many control strategies that are used to emulate inertia response with most the applications that integrating the wind and solar power are recommending the use of BESS as the main source of that response [16],[17],[18]. However, MPPT could be more advantageous to be used for a single or a remote turbine or a small group of solar panel technique, since it does not require any further resources like BESS or an additional maintenance cost. Nevertheless, for an aggregated number of wind turbines or a large number of solar panels, BESS could be the recommended option since it is a unique choice for many problems that are related to integrating RES [19]-[20] as it is mentioned earlier. Additionally, the inertia constant $(H)$ is controllable when using BESS emulation control techniques whereas it is variable and depend mostly on the operational limitation that it is obtained from VSWT. To conclude, using BESS for supporting the control of declining inertia and the problem of fluctuation in wind energy and the other sources of RES could be more feasible and a better option than relying on the pitch control of the individual wind turbine. Furthermore, if it is used to mitigate the fluctuation, BESS also participates in supporting other ancillary services such as PFC and Automatic Generation Control (AGC).

\section{GRID-SCALE BESS MODEL}

BESS mainly consists of the following components: (i) the energy storage model which is developed to store/restore energy. It is the typical conversion system that basically uses the classical electrochemical conversion (ii) A power electronic converter model (inverter/rectifier) which is essential to transform the DC-voltage from the energy storage part to the AC-voltage conditions and vice versa. (iii) A set of controllers gets configured in the connection between the energy storage part, the power converter, and the network. The main idea is to allow the proper operation of the energy storage system and control procedures. A description of those components is made available in the next subsections. Fig. 1 shows a representative diagram of the main above described components. Also, the figure embraces all the BESS circuit parameters. 


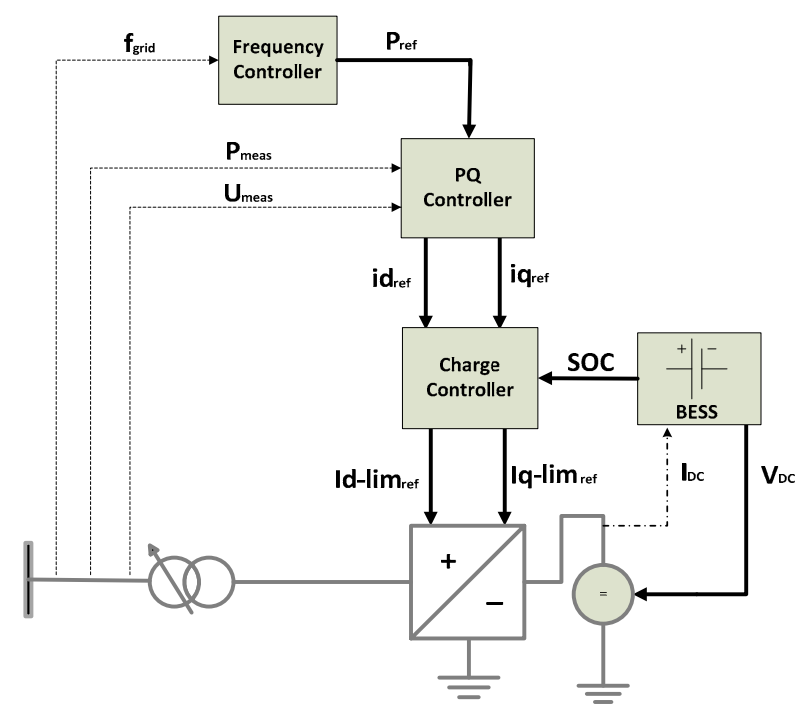

Fig. 1 A representative block diagram illustrating the BESS utilized in this simulation test.

\section{A. Battery model}

Modeling the energy storage part is one of the most challenging situations in the energy storage system. Rechargeable batteries are characterized by their reversible reaction with charge/discharge processes with many dynamically changing parameters such as the State of Charge (SOC), terminal voltage, internal resistance, and temperature.

Therefore, no accurate electrical battery model serves all the purposes to study the dynamic behavior of all the existing commercial batteries. However, an approximate model is already used in many applications with proven results. Fig. 2 shows two circuit equivalent battery model [21] that is used in this analysis study.
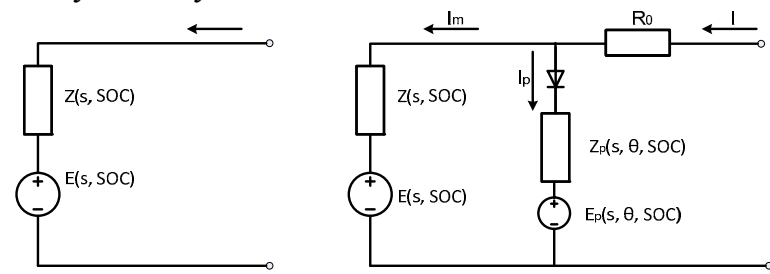

Fig. 2 Circuit equivalent model representative of an electric battery [21] (a) Simple model without parasitic reaction

(b) including the parasitic reaction effect

In this model, the main parameter SOC is calculated using an integrator which takes into account the current of the battery $\left(I_{b a t}\right)$ :

$$
U_{d c}=U_{\max } S O C+U_{\max }(1-S O C)-I_{b a t} Z_{i}
$$

where: $U_{\min }$ is the cell voltage discharged cell (V), $U_{\max }$ is the maximum voltage.

Table I lists all the values for the battery parameters that are set in DIgSILENT battery module for the use in all the simulation case studies in this paper.

\section{B. Power converter model}

The model represents a voltage source AC/DC two-level converter (capacitive dc circuit). This article is focused on the power system stability, so the center of interest is the control behavior of PWM-converter instead of switching frequencies, or high frequencies phenomenon. For this reason, the equivalent to the fundamental frequency models is used with PWM converter which operated in a stator voltage oriented reference frame. Hence, $d$-axis represents the active and $q$-axis the reactive component. The line-line $\mathrm{AC}$ voltage (rms value, $\left.U_{A C}=U_{A C, d}+j U_{A C, q}\right)$ and DC voltage $\left(U_{d c}\right)$ are related by:

$U_{A C, d}=\frac{\sqrt{3}}{2 \sqrt{2}} m_{d} V_{d c} \quad U_{A C, q}=\frac{\sqrt{3}}{2 \sqrt{2}} m_{q} V_{d c}$

where $m_{d}$ and $m_{q}$ are the real and imaginary part of the modulation index.

TABLE I

BESS PARAMETERS VALUES

\begin{tabular}{|l|c|}
\hline \multicolumn{1}{|c|}{ Parameters } & Value \\
\hline SOC -state of change & 0.8 \\
\hline Single Cell Capacity & $1.2 \mathrm{Ah}$ \\
\hline Min. Voltage of empty cell $\left(U_{\min }\right)$ & $12 \mathrm{~V}$ \\
\hline max. Voltage of full cell $\left(U_{\max }\right)$ & 13.85 \\
\hline Number of parallel connected cells $\left(N_{p}\right)$ & 60 \\
\hline Number of parallel connected cells $\left(N_{s}\right)$ & 65 \\
\hline Nominal BESS Voltage $\left(U_{n}\right)$ & $0.9 \mathrm{kV}$ \\
\hline Internal Resistance per cell $\left(Z_{i}\right)$ & $0.001 \mathrm{ohm}$ \\
\hline
\end{tabular}

\section{Controllers models}

In the following subsections, a brief description for each of the four controllers is used in the simulation environment.

\section{1) Frequency controller}

This controller is a simple control loop added to the power converter controller; it creates an active power control signal (inertial power $P_{H s y n}$ ) based on the swing equation in (3):

$P_{H s y n}=2 H_{s y n} f_{s y s} \frac{d f_{s y s}}{d t}$

where $H_{s y n}$ express the synthetic or emulated inertia (sec) and $f_{\text {sys }}$ system frequency in per unit. Implementation this controller is depicted in Fig. 3.

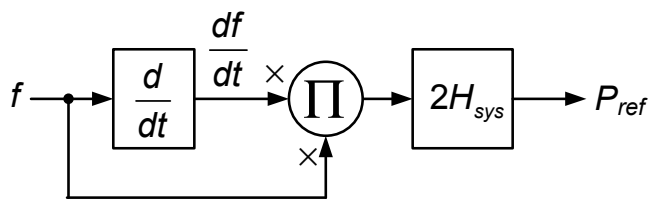

Fig. 3 Model of the Frequency Controller

\section{2) Charge controller}

The charge controller consists of two parts as they appear in Fig. 4a. The first part is the charging controller. The purpose of this controller is to achieve the described boundary conditions in Table II. The second block represents the limits the absolute value of the current order according to (1). From Fig. 1, the active current ( $d$-axis) always has higher priority than the reactive current ( $q$-axis) in the implementation of BESS for most applications of frequency regulation. The operation of this controller is shown in Fig. 5a. Table II list all the parameters for the controller that is used in this test.

\section{3) Current Controller}

The input currents to the controller are the converter's ACcurrents expressed in a reference $d q$ frame. The output signals 
$P_{m d}$ and $P_{m q}$ are defined in the same reference frame and transformed back to a global reference frame using the same reference angle. PI control loop regulates the $d$ and $q$-axis current components $\left(i_{d}, i_{q}\right)$ based on a PI controller regulating the active and reactive power $(P, Q)$, these are shown in Fig $4 b$.

TABLE II

CHARGE CONTROLLER PARAMETERS VALUES

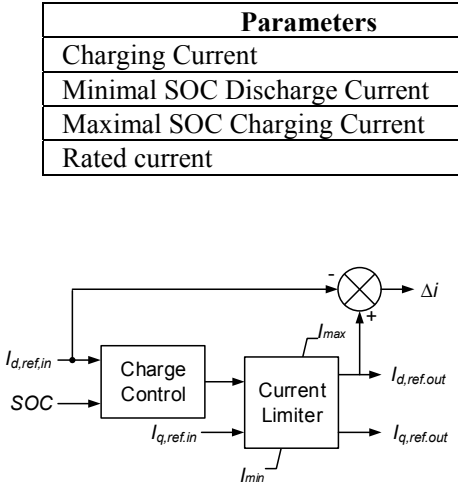

(a) Model of the Charge Controller

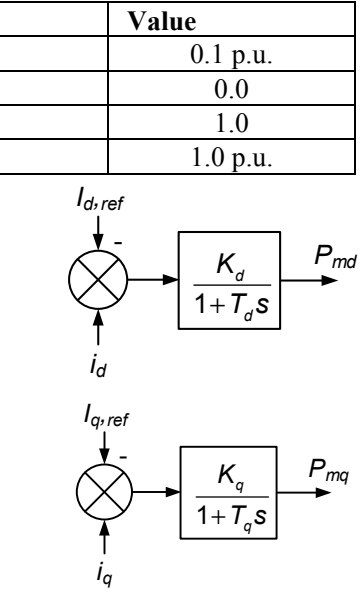

(b) Model of the current controllers

Fig. 4 Charger and current controllers.

\section{4) $P Q$ controller}

The controller for the active and reactive power is shown in Fig. 5 The voltage (or $Q$ ) controller has a very slow integercontroller for set point tracking and a slope with a deadband for proportional voltage support.

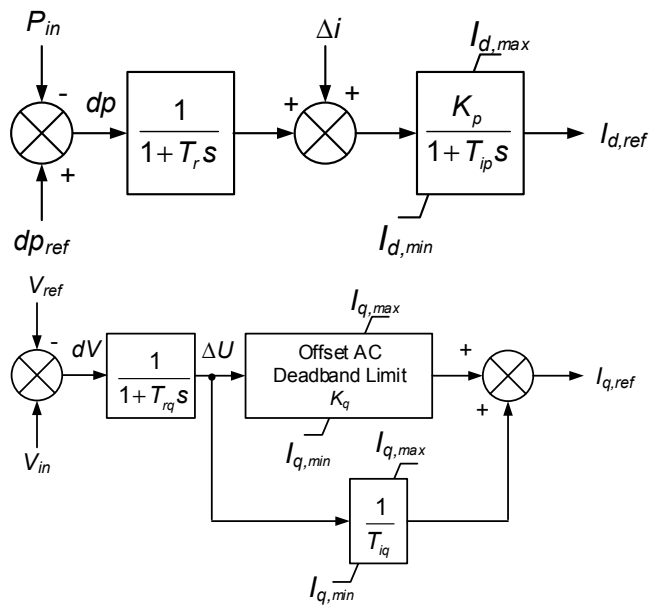

Fig. 5 Model of the PQ-Controller

\section{SimULATION AND RESULTS}

A test system model is designed by using DIgSILENT PowerFactory for the purpose of the simulation of three case studies as are discussed in the following three subsections. The grid consists of four main electrical power elements. A synchronous generator machine with a capacity of 500 MVA and a load with active and reactive powers of $90 \mathrm{MW}$ and 30
MVAR respectively. A transmission line of $0.5 \mathrm{~km}$ length is connected to the main buses 1 and 2 as appears in Fig. 6. The grid is operated at $50 \mathrm{~Hz}$ and $230 \mathrm{kV}$ AC voltage. Additionally, all the operational parameters of the grid-scale battery are set at the values as listed in Table I. Furthermore; all the necessary controllers are created as described in section III using DIgSILENT Simulation Language (DSL) a control modeling tool.

Fig. 6 displays the steady-state values for all grid parameters including the dispatched active and reactive powers of the synchronous machine 93.8 MW and 27 MVar respectively. It also shows the battery in a charging mode and absorbing $2.5 \mathrm{MW}$ of active power from the generator before the disturbance event.

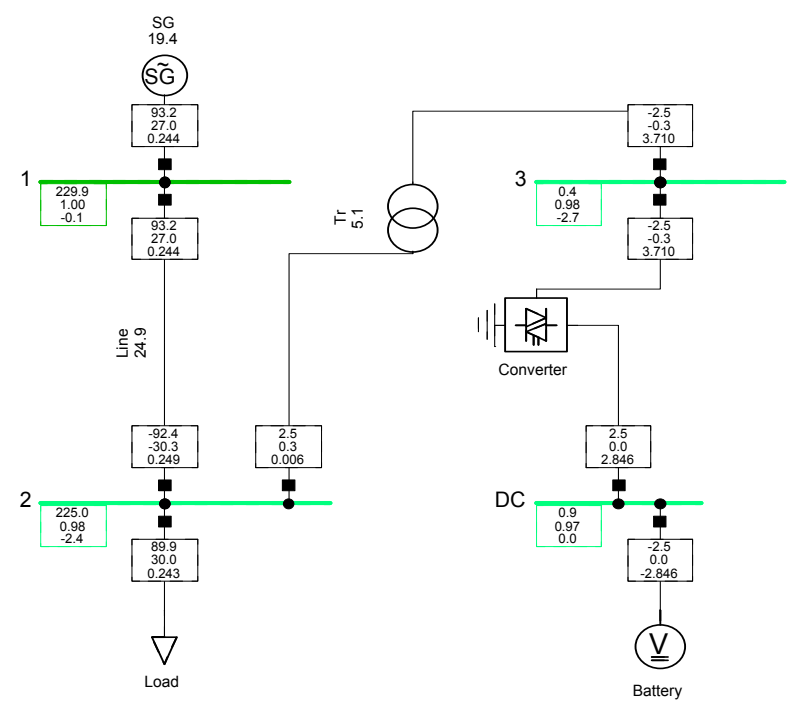

Fig. 6 Test model for one machine power system.

Before the start of the three case studies, a simple test scenario is carried on to verify the system with a disturbance event at the moment of time (1 sec) shortly after the start of the simulation. The simulation continues for 10 seconds for this test, and this is also the case with all other case studies. The purpose of this test is to show the frequency response for BESS at the synthetic inertial response $\left(\mathrm{H}_{\mathrm{syn}}\right)$ equal to 50 . Fig. 7 shows the simulation results considering a sudden increase in the load demand. Simulation results show how the BESS injects more power into the transmission system during the under-frequency disturbance. However, the frequency continues to decline to reach a steady-state value at 0.995 p.u. $(49.75 \mathrm{~Hz})$. However, since there are no other ancillary services such as primary or secondary control installed in this test environment, the frequency stays as its study-state value with aid from the synthetic inertial response from BESS.

\section{A. Impact of Gain of Synthetic Inertial controller $\left(H_{s y n}\right)$}

In this case study, the synthetic inertial response for the BESS controller is changed from zero to 500 in step of 10 in each case. The other two elements parameters are retained at a fixed value (i.e. transmission line impedance and load). The test is designed to show the system frequency response of the grid considering the changes in the gain of the synthetic 
inertial controller of the BESS.

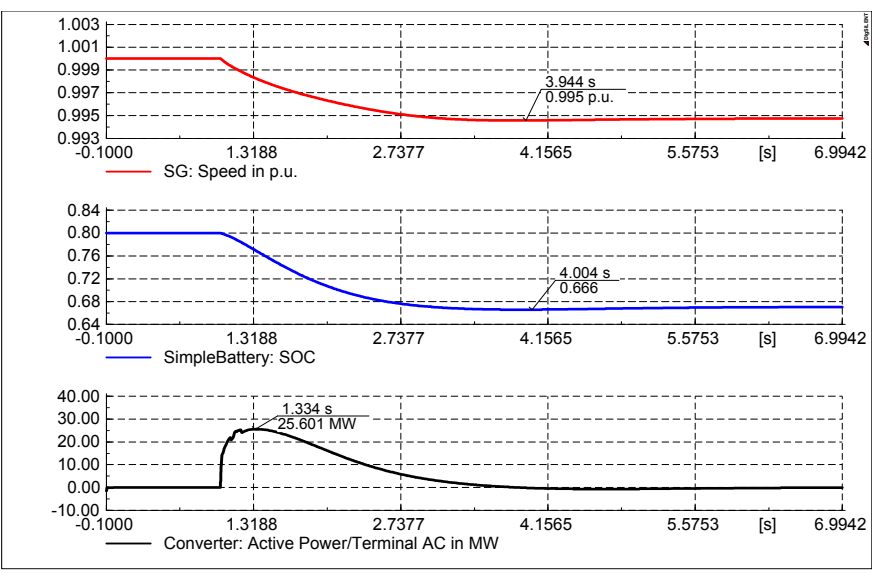

Fig. 7 Simulation results for a simple test BESS including Emulating Inertia Response.

From Fig. 8, it is evident that increasing the gain of the synthetic inertia controller which, in turn, improves the IR for the grid and provides a better frequency support. However, it also must be noticed that extremely high gain of the synthetic inertial controller tends to discharge the BESS quickly.
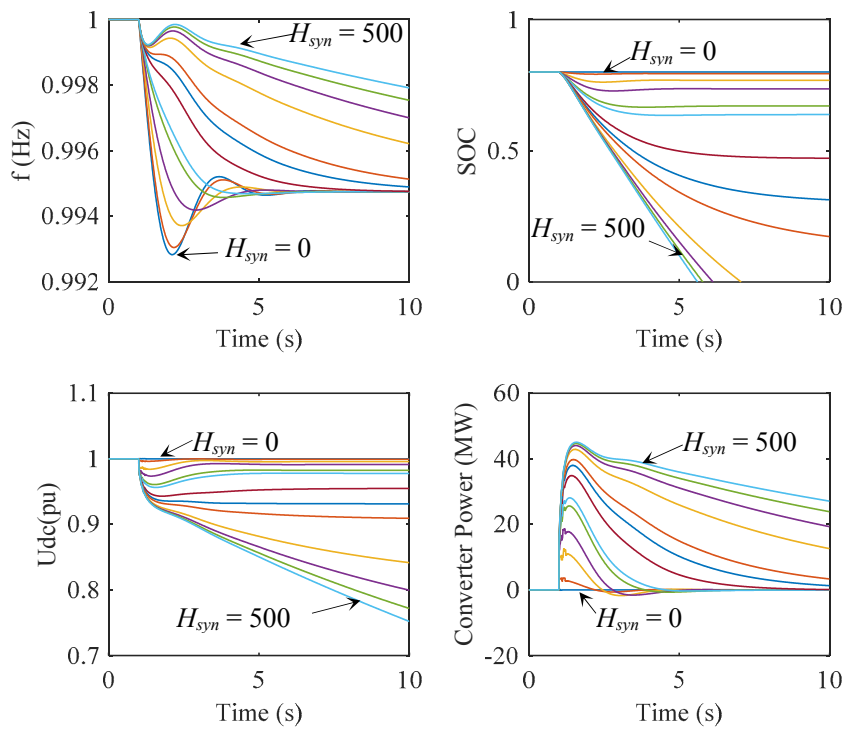

Fig. 8 Simulation results for case study 1 Hsyn $=0,1,5,10,20,25,50,75,100,200,300,400,500$.

Therefore, this situation could degenerate into another frequency disturbance because of the drop in power injection of the BESS. Additionally, the results also show that when the gain of the inertial response is high, this deviates the value of the frequency to above of its nominal value. Therefore, it is a necessary to control the gain of BESS IR controller in order to function properly in coordination with other frequency controls to stabilize the grid frequency.

\section{B. Impact of size of disturbance $\left(\Delta P_{L}\right)$}

The second set of test scenarios is designed to show the system frequency response of the transmission system in the event of a sudden disruption. The first simulation starts with
$\Delta P_{L}$ equal to zero. Other test scenarios performed by an increment in load in the step of 50MW up to $335 \mathrm{MW}$ as it appears in Fig. 9. The gain of the synthetic inertial controller $\mathrm{H}_{\text {syn }}$ is set at 50 . Simulation results of this test demonstrate that the size of the power imbalance that caused by sudden change in load demand $\Delta P_{L}$ has a significant and direct effect on the grid frequency dynamic. The power imbalance is creating by setting an event in DIgSILENT to simulate the sudden increase in load demand. Fig. 8 shows clearly that BESS handles the required inertial response and injects more active power to bring the frequency to an acceptable steady-state value for the first 10 cases. However for $\Delta P_{L}$ more than 200 MW increment, BESS fail to support the frequency recovery and not capable of bringing the frequency event to a steadystate. Similarly, SOC drops fast to zero at 5 and $10 \mathrm{sec}$. for $\Delta P_{L}$ values of 300 and $335 \mathrm{MW}$ respectively.
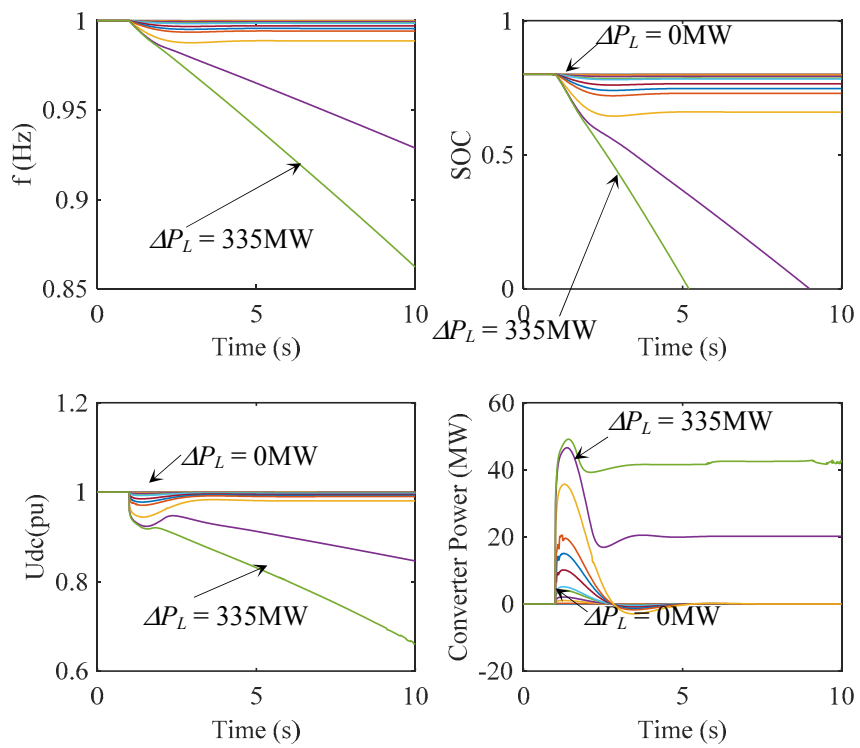

Fig. 9 Simulation results for case study 2 $\Delta P_{L}=0,1,5,10,20,25,50,75,100,200,300,335 \mathrm{MW}$.

\section{Impact of system robustness $\left(X_{L}\right)$}

The system robustness is represented by the total equivalent transmission system impedance $X_{L}$. If the transmission system is impedance is low $\left(X_{L} \rightarrow 0\right)$ the inertial power contribution by the BESS could effectively provide frequency support. However, weak transmission system has high impedance, interfering or affecting the power injection as a consequence. Therefore, the effectiveness of the inertial response given by the BESS is negatively affected. The test is designed to show the system frequency response of the transmission system considering the changes in total equivalent transmission system impedance $X_{L}$. the transmission line impedance $X_{L}$ is changed in each scenario in the sequence of increment. Meanwhile, $H_{s y n}$ is preserved at 50 in all test scenarios of this case study. Fig. 10 shows the simulation results for the third and last case study. The results show clearly that the frequency drops further at each increment in $X_{L}$. Similarly, the second graph indicates that the SOC drops faster with high transmission line impedance. This 
test clearly shows that changing the impedance of a transmission line is a strong evidence of the importance of the location of BESS on the transmission system.
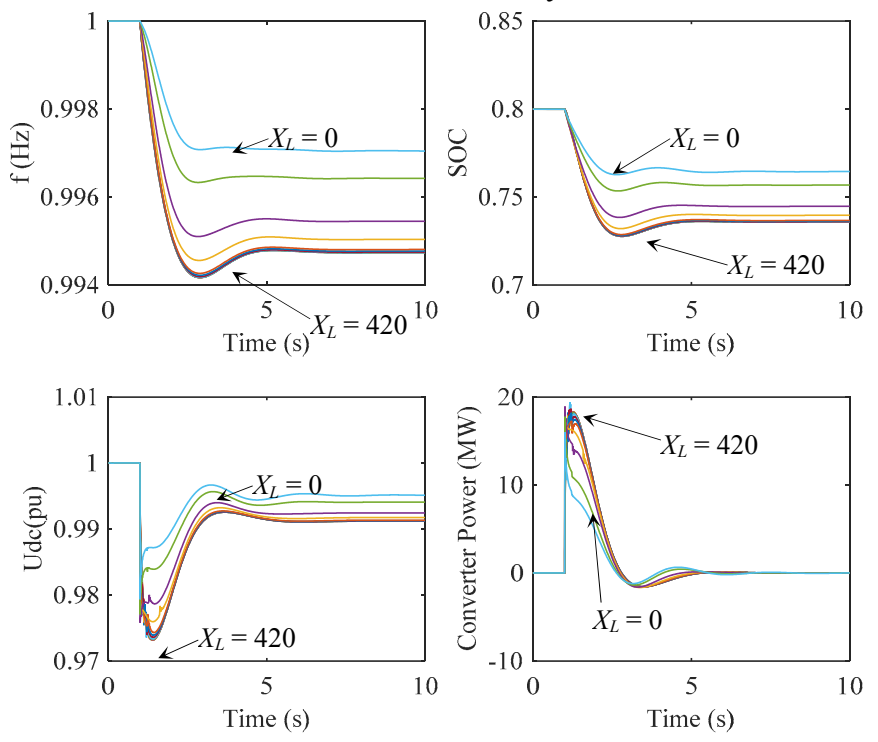

Fig. 10 Simulation results for case study 3 $X_{L}=0,1,5,10,20,25,50,75,100,200,300,400,420 \Omega$.

\section{CONCLUSIONS}

The purpose of this paper is to evaluate and investigate the effect of installing BESS on grid level transmission system to support fast inertial frequency response. In three case studies, different simulation scenarios were carried out to examine the effectiveness of using grid-scale BESS to provide the necessary inertial response to the grid. From the results, it clearly appears that BESS has high performance and characteristics for providing this service. The case studies simply show three significant contributions to the future use of BESS. Firstly, it shows clearly that no battery sizing optimization technique is valid without considering the inertial response of the BESS. Therefore, a real-time optimization technique is required to set the right value of the synthetic inertial response. Secondly, it proves that the inertial response controller should work in coordination with the other frequency control to stabilize the grid frequency in the future power system. Finally, it shows evidently that the location of BESS on the transmission line has a significant impact on the center of inertia of the system.

\section{REFERENCES}

[1] F. Gonzalez-Longatt, E. Chikuni, W. Stemmet, K. Folly, "Effects of the synthetic inertia from wind power on the total system inertia after a frequency disturbance," Power Engineering Society Conference and Exposition in Africa (PowerAfrica), IEEE, pp. 1 - 7, 2012.

[2] X. Li, Y. Huang, J. Huang, S. Tan, "Modeling and control strategy of battery energy storage system for primary frequency regulation," Power System Technology (POWERCON), 2014 International Conference, IEEE, pp. 543 - 549, 22 Oct. 2014.

[3] P. Wall, F. Gonzalez-Longatt, V. Terzija, "Estimation of generator inertia available during a disturbance," 2012 IEEE Power and Energy Society General Meeting, pp. 1 - 8, 2012.
[4] Sh. Chen, T. Zhang, H. B. Gooi, R. D. Masiello, "Penetration Rate and Effectiveness Studies of Aggregated BESS for Frequency Regulation," IEEE Transactions on Smart Grid, vol. 7, no. 1, pp. 167 - 177, Jan. 2016.

[5] H. Chena, Th. N. Conga, W. Yanga, Ch. Tanb, Y. Lia, Y. Dinga, "Progress in electrical energy storage system: A critical review," Science Direct, vol. 19, no. 3, p. 291-312, March 2009.

[6] F. Gonzalez-Longatt, "Impact of synthetic inertia from wind power on the protection/control schemes of future power systems: Simulation study," Developments in Power Systems Protection, DPSP 2012. 11th International Conference, pp. 1 - 6, 2012.

[7] F. Gonzalez-Longatt, "Frequency Control and Inertial Response Schemes for the Future Power Networks," in Large Scale Renewable Power Generation, Singapore, Springer, 2014, pp. 193-231.

[8] N. Ina, S. Yanagawa, T. Kato, and Y. Suzuoki, "Smoothing of PV system output by tuning MPPT control," Elect. Eng, Japan, vol. 2, no. 152 , pp. 10-17, 2005.

[9] Li H., Chen Z., "Overview of different wind generator systems and their comparisons," IET Renewable Power Generation, vol. 2, no. 2, pp. 123 - 138, June 2008.

[10] J. Morren, S. W. H. de Haan, W. L. Kling, and J. A. Ferreira, "Wind turbines emulating inertia and supporting primary frequency control," IEEE Trans. Power System, vol. 21, no. 1, pp. 433-434, 2006.

[11] H. Ye, W. Pei, Z. Qi, "Analytical Modeling of Inertial and Droop Responses From a Wind Farm for Short-Term Frequency Regulation in Power Systems," IEEE Power \& Energy Society, vol. PP, no. 99, pp. 1 10,2015 .

[12] K. Prompinit, S. Khomfoi, "Design of Active Power Controller of a $\mathrm{BESS}$ in $\mathrm{AC}, "$ in ECTI-CON 12th International Conference, Hua Hin, 24-27 June 2015 .

[13] Y. G. Rebours, D. S. Kirschen, M. Trotignon, S. Rossignol, "A Survey of Frequency and Voltage Control Ancillary Services-Part I: Technical Features," IEEE Transactions on Power Systems, vol. 22, no. 1, pp. 350 - 357, Feb. 2007.

[14] B. Singh, Z. Hussain, "Application of Battery Energy Storage System (BESS) in voltage control and damping of power oscillations," in 2010 5th International Conference on Industrial and Information Systems, Mangalore, July 29 2010-Aug. 12010.

[15] M. P. N van Wesenbeeck, S. W. H. de Haan, P. Varela, K. Visscher, "Grid-tied converter with virtual kinetic storage," in PowerTech, IEEE, Bucharest, 2009.

[16] J. Servotte, E. Acha, L. M. Castro, "Smart frequency control in power transmission systems using a BESS," in Smart Grid Technologies Asia (ISGT ASIA), 2015 IEEE Innovative, Bangkok, 2015.

[17] T. Xia, M. Li, P. Zi, L. Tian, "Modeling and Simulation of Battery Energy Storage System (BESS) Used in Power System," in 5th International Conference on Electric Utility Deregulation and Restructuring and Power Technologies (DRPT), Changsha, 2015.

[18] Sh. Chen, T. Zhang, H. B. Gooi, R. D. Masiello, "Penetration Rate and Effectiveness Studies of Aggregated BESS for Frequency Regulation," IEEE Transactions on Smart Grid, vol. 7, no. 1, pp. 167 - 177, 2016.

[19] H. Zhao, Q. Wu, S. Huang, Q. Guo, "Optimal siting and sizing of Energy Storage System for power systems with large-scale wind power integration," PowerTech, 2015 IEEE Eindhoven, pp. 1 - 6, June 29 2015-July 22015.

[20] M. Lawder, B. Suthar, P. Northrop, S. De, C. Hoff, O. Leitermann, M. Crow, S. Santhanagopalan, V. Subramanian, "Battery Energy Storage System (BESS) and Battery Management System (BMS) for Grid-Scale Applications," Proceedings of the IEEE, vol. 102, no. 6, pp. 10141030, 2014.

[21] M. Chen, G. A. Rincon-Mora, "Accurate electrical battery model capable of predicting runtime and $\mathrm{I}-\mathrm{V}$ performance," IEEE Transactions on Energy Conversion, vol.21, no.2, pp. 504 - 511, 2006. 